\title{
Ciclopirox induces autophagy through reactive oxygen species-mediated activation of JNK signaling pathway
}

\author{
Hongyu Zhou ${ }^{1,2}$, Tao Shen ${ }^{2}$, Chaowei Shang ${ }^{2}$, Yan Luo ${ }^{2}$, Lei Liu' ${ }^{2}$, Juming Yan ${ }^{1}$, \\ Yan $\mathbf{L i}^{1}$, Shile Huang ${ }^{2,3}$ \\ ${ }^{1}$ State Key Laboratory of Phytochemistry and Plant Resources in West China, Kunming Institute of Botany, Chinese Academy \\ of Sciences, Kunming 650201, China \\ ${ }^{2}$ Department of Biochemistry and Molecular Biology, Louisiana State University Health Sciences Center, Shreveport, \\ LA 71130-3932, USA \\ ${ }^{3}$ Feist-Weiller Cancer Center, Louisiana State University Health Sciences Center, Shreveport, LA 71130-3932, USA \\ Correspondence to: \\ Shile Huang, e-mail: shuan1@Isuhsc.edu \\ Yan Li, e-mail: liyanb@mail.kib.ac.cn \\ Keywords: Ciclopirox, autophagy, rhabdomyosarcoma, reactive oxygen species, JNK \\ Received: August 11,2014 Accepted: September 06, 2014 Published: October 04, 2014
}

\section{ABSTRACT}

Ciclopirox olamine (CPX), a fungicide, has been demonstrated as a potential anticancer agent. However, the underlying anticancer mechanism is not well understood. Here, we found that CPX induced autophagy in human rhabdomyosarcoma (Rh30 and RD) cells. It appeared that CPX-induced autophagy was attributed to induction of reactive oxygen species (ROS), as N-acetyl-L-cysteine (NAC), a ROS scavenger and antioxidant, prevented this process. Furthermore, we observed that CPX induced activation of mitogen-activated protein kinases (MAPKs), including extracellular signal-regulated kinase $1 / 2$ (ERK1/2), c-Jun $\mathbf{N}$-terminal kinase (JNK) and p38 MAPK, which was also blocked by NAC. However, only inhibition of JNK (with SP600125) or expression of dominant negative c-Jun partially prevented CPX-induced autophagy, indicating that ROS-mediated activation of JNK signaling pathway contributed to CPX-induced autophagy. Of interest, inhibition of autophagy by chloroquine (CQ) enhanced CPX-induced cell death, indicating that CPX-induced autophagy plays a pro-survival role in human rhabdomyosarcoma cells. Our finding suggests that the combination with autophagy inhibitors may be a novel strategy in potentiating the anticancer activity of CPX for treatment of rhabdomyosarcoma.

\section{INTRODUCTION}

Ciclopirox olamine (CPX) (also called Batrafen, Loprox, Penlac and Stieprox), a synthetic hydroxypyridone derivative, is currently used for the treatment of superficial fungal infections and available in a variety of formulations, including cream, lotion, gel, nail lacquer and shampoos [1]. CPX has a broad spectrum of action against dermatophytes, yeast, filamentous fungi and bacteria. Mechanistically, CPX has been proposed to act as an iron chelator, forming complexes with trivalent metal cations, such as $\mathrm{Fe}^{3+}$, and inhibiting metal-dependent enzymes, such as catalase and peroxidase, which play an essential role in the intracellular degradation of toxic peroxides, though this remains to be determined [2]. Recent studies have shown that CPX induces cell death in different cancer cells, such as primary human acute myeloid leukemia cells, human breast cancer MDA-MB231 cells and human rhabdomyosarcoma Rh30 cells $[3,4]$. However, the mechanism by which CPX induces cancer cell death is only at the beginning to be investigated. Eberhard et al. reported that CPX displays preclinical anticancer activity against hematologic malignancies and induces cell death through its ability to chelate intracellular iron and inhibit the iron-dependent enzyme ribonucleotide reductase [4]. We showed that CPX inhibits tumor growth in human breast cancer MDA-MB231 xenografts and induces cell death through caspase-dependent and caspaseindependent mechanisms in Rh30 cells [3]. 
Autophagy is an evolutionarily conserved catabolic process that involves the degradation of the components of a cell through the lysosomal machinery [5]. During autophagy, a portion of the cytoplasmic materials and intracellular organelles are sequestered into a double membrane organelles known as autophagosomes, which degrade the sequestered contents by fusion with lysosomes to form autolysosomes [5]. Under some conditions, autophagy contributes to cellular survival by providing nutrients and energy to help cells adapt to starvation or stress (such as hypoxia, X-ray and anticancer drugs) [6]. However, under other settings, activated autophagy leads to cell death, called autophagic cell death or type II programmed cell death [6].

Increasing evidence has implicated that multiple stress conditions such as oxidative stress [7], endoplasmic reticulum (ER) stress [8] and pathogen infection [9], can induce autophagy through different molecular pathways. Among them, reactive oxygen species (ROS) function as signaling molecules not only in cell growth, differentiation, proliferation and apoptosis [10], but also in autophagy [11]. For example, hydrogen peroxide and 2-methoxyestradiol, two ROS-generating agents, can induce autophagic cell death in transformed HEK293 cells and cervical cancer (HeLa) cells [12]. Under starvation or oxidative stress conditions, ROS are increased and play a critical role in autophagosome formation through targeting cysteine protease Atg 4 [13]. Although the role of ROS in the regulation of autophagy has been confirmed, what signaling molecules involved in ROS-induced autophagy are still not well understood.

Mitogen-activated protein kinases (MAPKs) are evolutionarily conserved dual (Tyr and Ser/Thr) protein kinases, and play an important role in signal transduction from the cell surface to the nucleus [14]. To date, different groups of MAPKs have been characterized in mammals: the extracellular signal-regulated kinases ERK1/2, ERK3/4, ERK5, ERK7/8, the Jun N-terminal kinases JNK $1 / 2 / 3$ and the p38 MAPKs p $38 \alpha / \beta / \gamma / \delta$ [14]. Not only receptor-ligand interactions, but also different stress stimuli such as the oxidative stress caused by ROS, can induce potential activation of MAPK pathways [15]. Depending on the cell type and the stimulus, ERK signaling pathway mediates different cell responses, such as proliferation, apoptosis and autophagy [14-16]. Generally, growth factors may activate the RAS-RAF-MEK1/2-ERK1/2 pathway [14]. More recently, ERK5, also termed big mitogen-activated protein kinase-1 (BMK1), has been identified as a component of a parallel MAPK pathway, which is associated with a diverse range of cellular processes including cellular proliferation, migration, survival and angiogenesis [17]. The demonstration that the commonly used MEK1/2 inhibitors inactivated ERK5 suggested that ERK5 might regulate some of the cellular functions originally attributed to MEK1/2 [17, 18]. Studies have demonstrated that mammalian p38 MAPK has four isoforms: $\mathrm{p} 38 \alpha, \mathrm{p} 38 \beta, \mathrm{p} 38 \gamma$ and $\mathrm{p} 38 \delta$, of which $\mathrm{p} 38 \alpha$ is ubiquitously expressed, and best characterized [14,19]. p38 MAPK plays an essential role in the regulation of many cellular events including inflammation, cell growth, death, and differentiation $[14,19,20]$. Recently it has been found that p38 MAPK can also mediate autophagy in response to chemotherapeutic agents [21]. JNK, also known as the stress-activated protein kinase, has been implicated in apoptosis and autophagy [21-23]. In mammals, there are three JNK genes: JNK1, JNK2, and JNK3 [24]. JNK1 and JNK2 are ubiquitously expressed, while JNK3 is mainly expressed in brain, cardiac smooth muscle and testes [24]. In addition to apoptosis, JNK also contributes to autophagic induction in response to stress signals [21]. Particularly, ROS can induce JNK-dependent autophagy $[25,26]$.

Here we found that CPX induced autophagy in rhabdomyosarcoma ( $\mathrm{Rh} 30$ and $\mathrm{RD}$ ) cells, which was mediated by ROS induction, leading to activation of JNK cascade. Further, inhibition of autophagy by chloroquine (CQ) increased the cell death induced by CPX, indicating that CPX-induced autophagy played a pro-survival role in human rhabdomyosarcoma cells. Our findings suggest that combination treatment with CPX and pharmacological autophagy inhibitors might be a promising strategy for rhabdomyosarcoma therapy.

\section{RESULTS}

\section{CPX reduces cell viability and alters morphology in rhabdomyosarcoma cells}

To investigate the cytotoxicity of CPX in rhabdomyosarcoma cells, $\mathrm{RD}$ and $\mathrm{Rh} 30$ cells were treated with various concentrations of CPX for $72 \mathrm{~h}$, followed by MTS assay. As shown in Figure 1A, CPX decreased the cell viability in both RD and Rh30 cells in a concentration-dependent manner. By phase-contrast microscopic observation, more cells became round or detached from the culture plate when exposed to $20 \mu \mathrm{M}$ of CPX (Figure 1B). To determine whether CPX causes cell death by inducing apoptosis, cells were analyzed by flow cytometry following Annexin V-FITC and propidium iodide (PI) staining. As shown in Figure 1C, $20 \mu \mathrm{M}$ of CPX treatment for 48 and $72 \mathrm{~h}$ significantly increased the percentage of apoptotic cells compared with control cells.

\section{CPX induces autophagy in rhabdomyosarcoma cells}

Recently we have demonstrated that CPX induces caspase-dependent and independent cell death in Rh30 cells [3]. Since autophagy contributes to cell death in some cases [6], here we studied whether CPX induces autophagy in the cancer cells. Autophagy is characterized 
A

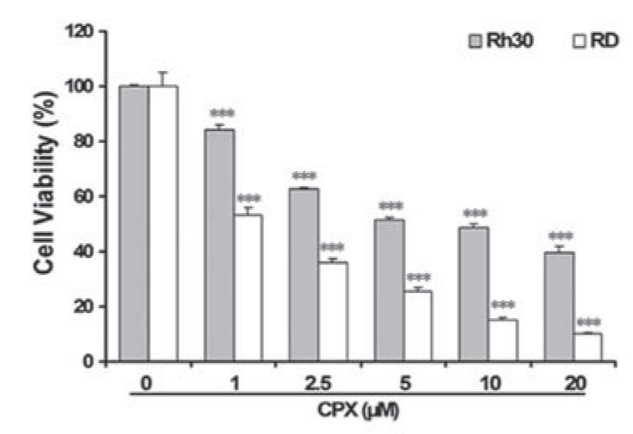

c
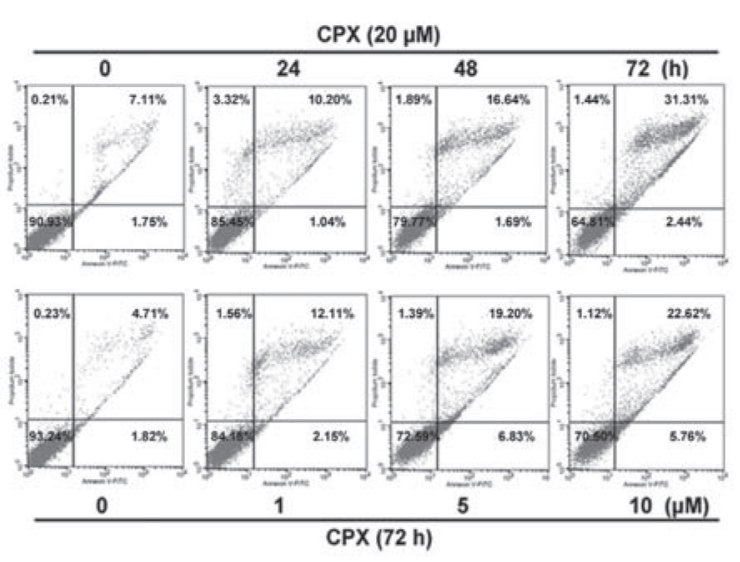

B

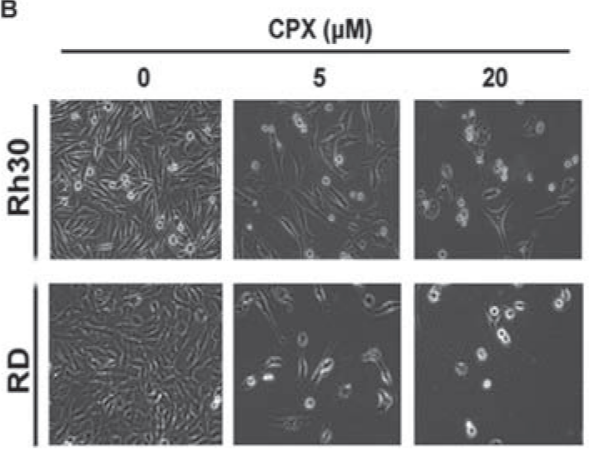

D
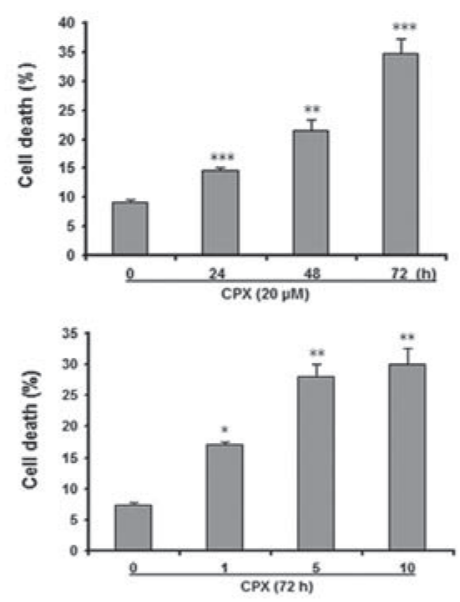

Figure 1: CPX decreases cell viability in rhabdomyosarcoma cells. (A) RD and Rh30 cells were treated with indicated concentrations of CPX for $72 \mathrm{~h}$. Cell viability was determined by MTS assay. (B) Rh30 and RD cells were treated with 5 and $20 \mu \mathrm{M}$ of $\mathrm{CPX}$ for $72 \mathrm{~h}$, followed by taking images under an Olympus inverted phase-contrast microscope equipped with the Quick Imaging system. (C) RD cells were treated with 0 and $20 \mu \mathrm{M}$ of CPX for $0-72 \mathrm{~h}$ or incubated with $0-10 \mu \mathrm{M}$ of CPX for $72 \mathrm{~h}$. The cells were then harvested and processed for Annexin V-FITC/PI staining and flow cytometry. Results are presented as mean $\pm \mathrm{SD}(\mathrm{n}=3) .{ }^{*} P<0.05,{ }^{* *} P<0.01$, ${ }^{* * *} P<0.001$, difference versus control group.

by the increased acidic vesicular organelles (AVOs), which are correlated with increased autophagosomes. We therefore investigated whether CPX could induce autophagy by staining with acridine orange (AO) in RD cells. As shown in Figure 2A, $20 \mu \mathrm{M}$ of CPX treatment for $24 \mathrm{~h}$ or $48 \mathrm{~h}$ induced the accumulation of $\mathrm{AVO}$ in the cytoplasm of RD cells.

LC3 is associated with the formation of the autophagosome membrane and is a specific marker for autophagy initiation [5]. Under normal conditions, LC3 is distributed homogeneously in the cytoplasm; when autophagy is induced, LC3 is recruited to the autophagosomal membrane and shows characteristic of GFP-LC3 puncta [5]. To elucidate whether CPX induced autophagy in rhabdomyosarcoma cells, the effect of CPX on the cellular localization of LC3 using Rh30 cells stably expressing GFP-LC3 was evaluated. As shown in Figure 2B, CPX treatment induced a punctuated fluorescent pattern of LC3, whereas untreated cells manifested a diffuse distribution of GFP-LC3, suggesting that CPX indeed induced autophagy in the cells.

Since LC3-I is converted to the hallmark autophagosome-associating protein LC3-II, expression of LC3-II has been widely used for monitoring autophagy [27]. To verify the above finding, we further tested whether CPX increases LC3-II protein level. The Western blotting results indicated that CPX potently increased LC3-II level in a time- and concentrationdependent manner in RD cells (Figure 2C). Moreover, induction of autophagy by CPX was identified by assessing the expressions of Beclin-1, a key regulator of autophagosome formation and p62/SQSTM1, a protein facilitating autophagic degradation of ubiquitinated protein aggregation [28]. CPX treatment decreased the expression of p62, but did not affect Beclin-1 expression (Figure 2C). Taken together, these results demonstrate that CPX induces autophagy in rhabdomyosarcoma cells. 

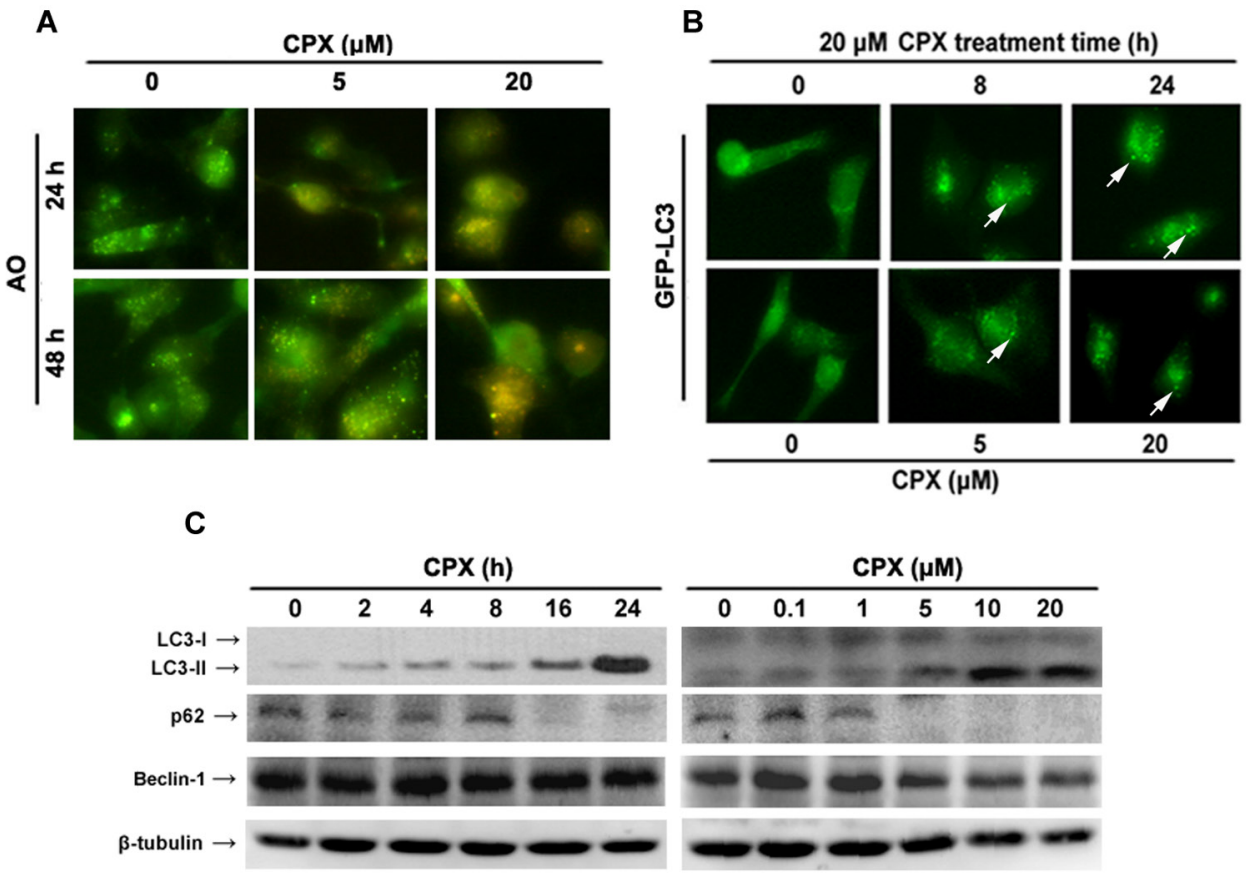

Figure 2: CPX induces autophagy in rhabdomyosarcoma cells. (A) Representative images of AO staining of RD cells following treatment with $0-20 \mu \mathrm{M}$ of CPX for 24 and $48 \mathrm{~h}$. Red color intensity shows acidic vesicular organelles, representing autophagolysosomes. (B) Representative micrographs of cells that show GFP-LC3 localization. Rh30 cells stably expressing GFP-LC3 were treated without or with $20 \mu \mathrm{M}$ of CPX for indicated time (Upper panel), or with indicated concentrations of CPX for $24 \mathrm{~h}$ (Bottom panel), and then visualized under a fluorescent microscope. Control cells presented a diffuse distribution of GFP-LC3, whereas CPX-treated cells displayed a punctate pattern of GFP-LC3 expression (arrows), indicating formation of autophagosomes. (C) Western blot analysis of autophagy-related proteins. $\mathrm{RD}$ cells were treated without or with $20 \mu \mathrm{M}$ of CPX for indicated time, or with indicated concentrations of CPX for $24 \mathrm{~h}$. The cells were harvested and subjected to Western blot analysis using indicated antibodies. $\beta$-tubulin was used as a loading control.

\section{CPX induces autophagy via ROS induction}

Growing evidence shows that ROS are important regulators of autophagy under various conditions [11]. To determine whether CPX-induced autophagy is associated with ROS induction, we first measured ROS level in both RD and Rh30 cells treated with CPX using the ROS-detecting fluorescent dye $\mathrm{CM}-\mathrm{H}_{2}$ DCFDA. ROS accumulation was observed after CPX treatment with the culturing time, and increased $\sim 2$-fold after $24 \mathrm{~h}$ of CPX $(20 \mu \mathrm{M})$ treatment in Rh30 cells (Figure 3A). Similar results were seen in RD cells (Figure 3B). Addition of $5 \mathrm{mM}$ of NAC, a ROS scavenger, almost completely blocked CPX-induced ROS in both Rh30 and $\mathrm{RD}$ cells (Figure $3 \mathrm{C}$ and $3 \mathrm{D}$ ). Interestingly, pretreatment with NAC remarkably attenuated CPX-induced GFP-LC3 puncta formation (Figure 3E) and LC3-II expression in the cells (Figure 3F), indicating that CPX-induced autophagy is mediated by ROS induction.

\section{ROS-mediated JNK activation contributes to CPX-induced autophagy}

ROS have been demonstrated as an inducer or mediator for the activation of MAPK family members, including JNK, p38 and ERK1/2 [14]. Also, studies have shown that MAPKs play a pivotal role in autophagy [16, 21, 29]. In this study, we observed that CPX induced phosphorylation of p38a (Thr180/Tyr182), ERK1/2 and JNK1/2 (Thr183/Tyr185) in a concentration-dependent manner (Figure 4A). Thus, we next asked whether CPXinduced autophagy involves these MAPKs. To this end, selective inhibitors of ERK1/2, p38 and JNK were employed. As shown in Figure 4B, pretreatment with U0126, a highly selective inhibitor of MEK $1 / 2$ (upstream kinases of ERK1/2), or doramapimod (also named BIRB 796), a highly selective p38 a MAPK inhibitor [30], markedly suppressed CPX-induced phosphorylation of ERK1/2 or p38, respectively. However, neither of the inhibitors apparently affected CPX-induced LC3-II expression, suggesting that ERK1/2 and p38 MAPK are not involved in CPX-induced autophagy. By contrast, presence of JNK inhibitor, SP600125, potently inhibited the activation of JNK pathway and LC3-II expression induced by CPX (Figure 4D). To further confirm the role of JNK signaling pathway in CPX-induced autophagy, RD cells were infected with recombinant adenovirus encoding FLAG-tagged dominant negative c-Jun (Ad-c-Jun-DN) or Ad-GFP (as control), and then treated with CPX for $24 \mathrm{~h}$. As shown in Figure 4E, ectopic expression of dominant 

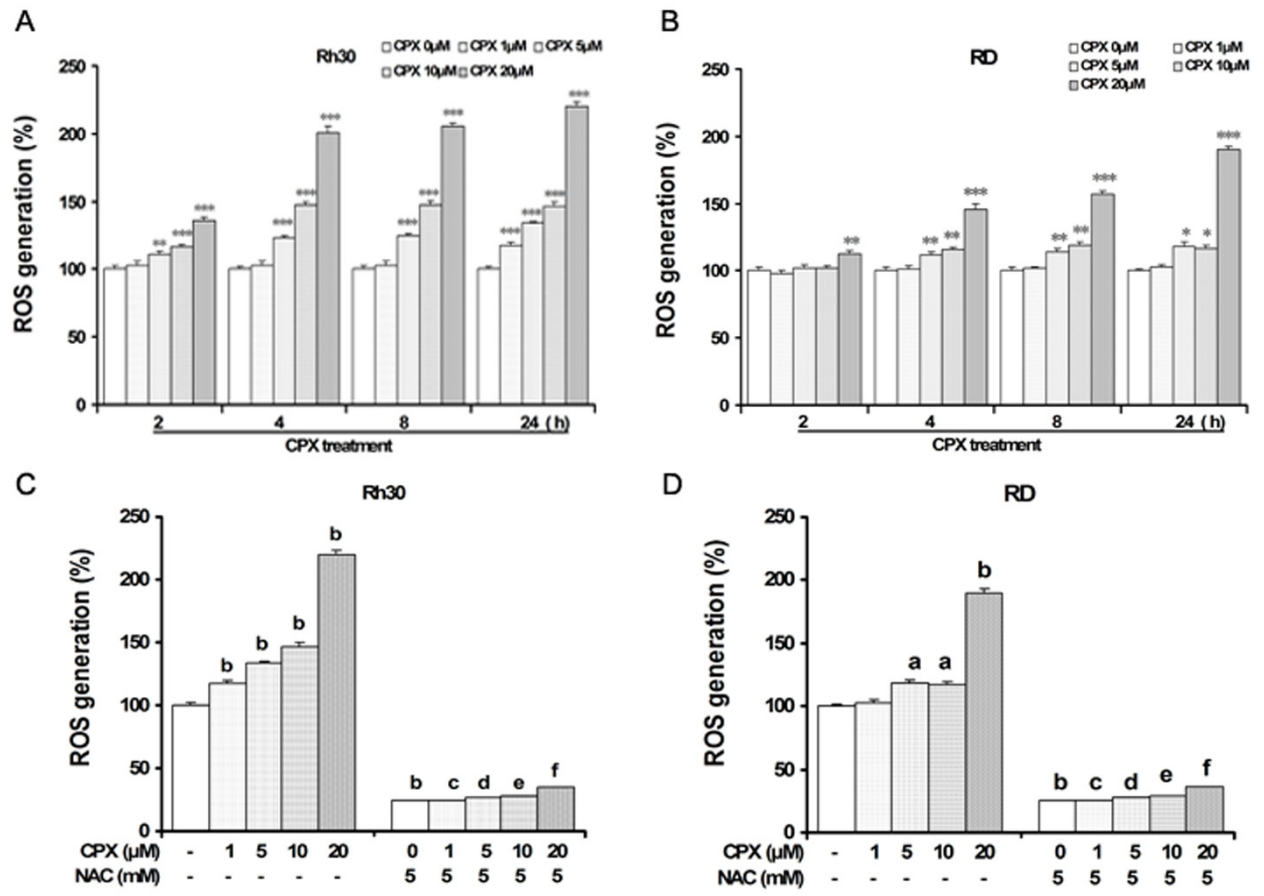

D

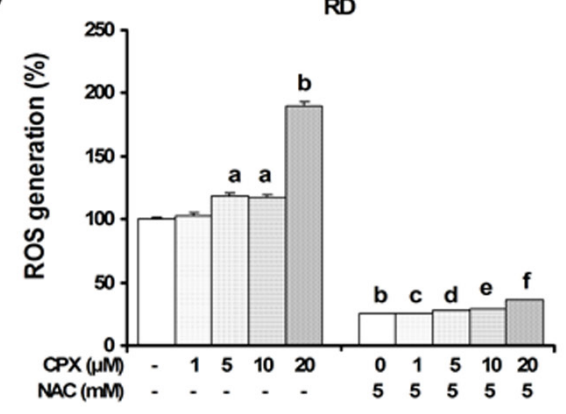

$\mathrm{E}$

$\mathrm{F}$
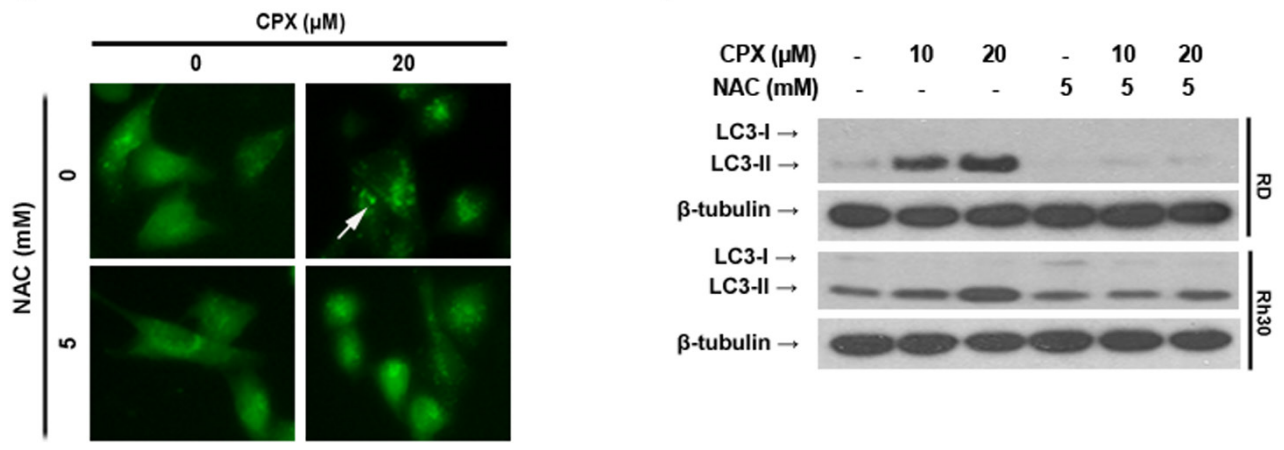

Figure 3: CPX increases intracellular level of ROS, thereby inducing autophagy. (A) and (B) RD and Rh30 cells were treated without or with different concentrations of CPX $(1-20 \mu \mathrm{M})$ for $30 \mathrm{~min}$, followed by loading with $10 \mu \mathrm{M}$ of CM-H ${ }_{2} \mathrm{DCFDA}$ for indicated time. Fluorescent intensity was detected using a microplate reader. Results are presented as $\operatorname{mean} \pm \mathrm{SD}(\mathrm{n}=3)$. ${ }^{*} P<0.05$, ${ }^{* *} P<0.01,{ }^{* * *} P<0.001$, difference versus control group. (C) and (D) RD and Rh30 cells were pre-incubated with or without NAC $(5 \mathrm{mM})$ for $30 \mathrm{~min}$, and then treated with or without various concentrations of CPX $(0-20 \mu \mathrm{M})$ for 30 min, followed by loading with $10 \mu \mathrm{M}$ of $\mathrm{CM}-\mathrm{H}_{2}$ DCFDA for $8 \mathrm{~h}$. Fluorescent intensity was detected using a microplate reader. Results are presented as mean $\pm \mathrm{SD}(\mathrm{n}=3)$. ${ }^{\mathrm{a}} P<0.05,{ }^{\mathrm{b}} P<0.01$, difference versus control group. ${ }^{\mathrm{c}} P<0.001$, difference versus $1 \mu \mathrm{M} \mathrm{CPX}$ group, ${ }^{\mathrm{d}} P<0.001$, difference versus $5 \mu \mathrm{M}$ CPX group, ${ }^{\mathrm{e}} P<0.001$, difference versus $10 \mu \mathrm{M}$ CPX group, ${ }^{\mathrm{f}} P<0.001$, difference versus $20 \mu \mathrm{M}$ CPX group. (E) Rh30 cells stably expressing GFP-LC3 were pretreated with $5 \mathrm{mM}$ of NAC for $1 \mathrm{~h}$, and then incubated with 0 and $20 \mu \mathrm{M}$ of CPX for $24 \mathrm{~h}$. The cells were visualized under a fluorescent microscope. (F) RD and Rh30 cells were pretreated with $5 \mathrm{mM}$ of NAC for $1 \mathrm{~h}$, and then incubated with $0-20 \mu \mathrm{M}$ of CPX for $24 \mathrm{~h}$. The cells were harvested and subjected to Western blot analysis with indicated antibodies. $\beta$-tubulin was used as a loading control.

negative c-Jun substantially attenuated CPX-induced LC3-II, demonstrating that activation of JNK pathway contributes to CPX-induced autophagy.

To further investigate the role of ROS induction in CPX-induced autophagy and activation of JNK pathway, ROS scavenger NAC was utilized. We found that pretreatment with NAC ( $5 \mathrm{mM})$ obviously attenuated CPXinduced c-Jun phosphorylation and LC3-II expression (Figure 4F), indicating that CPX induces autophagy through ROS-mediated activation of JNK signaling pathway.

\section{Autophagy plays a protective role in CPX-treated rhabdomyosarcoma cells}

Since autophagy has dual roles in cell survival and cell death $[6,31]$, to determine whether CPXinduced autophagy is pro-survival or pro-death in 


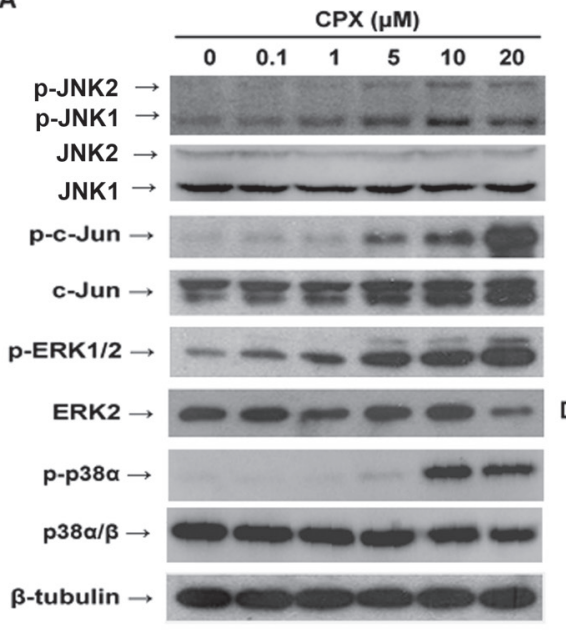

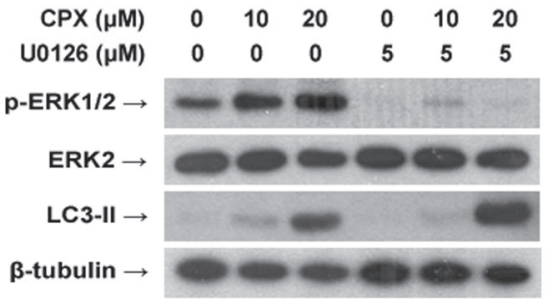

C

$\begin{array}{lllllll}\operatorname{CPX}(\mu \mathrm{M}) & 0 & 10 & 20 & 0 & 10 & 20\end{array}$

Doramapimod $(\mu \mathrm{M}) \quad 0 \quad 0000.5 \quad 0.5 \quad 0.5$

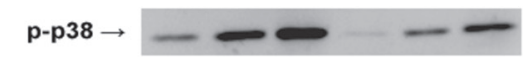

$\mathrm{p} 38 \rightarrow-\infty-\infty$

LC3-II $\rightarrow--\infty-\infty=$

B-tubulin $\rightarrow-\infty-\infty-\infty$

E
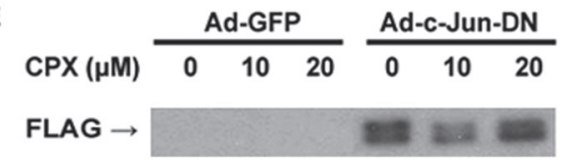

p-c-Jun $\rightarrow \quad$-की

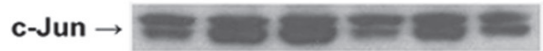

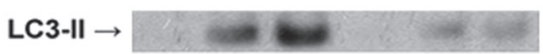

$\beta$-tubulin $\rightarrow$

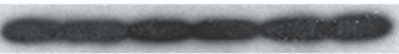

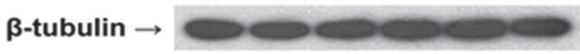

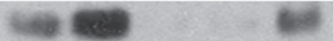

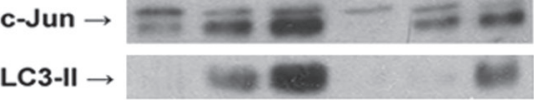

F

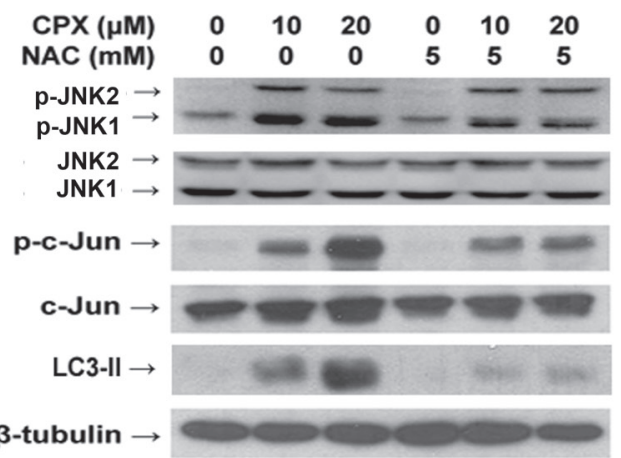

Figure 4: ROS-activated MAPKs pathway and JNK pathway contributes to CPX-induced autophagy. (A) RD cells were incubated with different concentrations of CPX for $24 \mathrm{~h}$, followed by Western blot analysis with indicated antibodies. (B) and (C) RD cells were pretreated with $\mathrm{U} 0126(5 \mu \mathrm{M})$ or doramapimod $(0.5 \mu \mathrm{M})$ for $1 \mathrm{~h}$, and then incubated with $0-20 \mu \mathrm{M}$ of CPX for $24 \mathrm{~h}$, followed by Western blot analysis with indicated antibodies. (D) RD cells were pretreated with SP600125 $(20 \mu \mathrm{M})$ for $1 \mathrm{~h}$, and then incubated with 0-20 $\mu \mathrm{M}$ of CPX for $24 \mathrm{~h}$. The cells were harvested and subjected to Western blot analysis with indicated antibodies. (E) RD cells were infected with Ad-c-Jun-DN or Ad-GFP for $24 \mathrm{~h}$, and then treated with CPX for $24 \mathrm{~h}$. The cells were harvested and subjected to Western blot analysis with indicated antibodies. (F) NAC attenuated CPX-induced JNK activation and autophagy. RD cells were pretreated with NAC $(5 \mathrm{mM})$ for $1 \mathrm{~h}$, and then incubated with $0-20 \mu \mathrm{M}$ of CPX for $24 \mathrm{~h}$. The cells were harvested and subjected to Western blot analysis with indicated antibodies. $\beta$-tubulin was used as a loading control in A-F.

rhabdomyosarcoma cells, $\mathrm{CQ}$, a pharmacologic autophagy inhibitor [5,6], which inhibits the late autophagic process by blocking the fusion of autophagosomes and lysosomes, was used. As expected, treatment with CQ alone increased LC3-II and p62 expressions (Figure 5A). CPX-induced LC3-II expression and p62 degradation were elevated in the presence of $5 \mu \mathrm{M}$ of CQ (Figure 5A). Importantly, MTS assay showed that inhibition of the late autophagic process with CQ $(5 \mu \mathrm{M})$ for $48 \mathrm{~h}$ reduced the cell viability very marginally, but potentiated the CPX-reduced cell viability significantly (Figure 5B). Furthermore, Annexin V-PI staining also demonstrated that $\mathrm{CQ}$ enhanced 


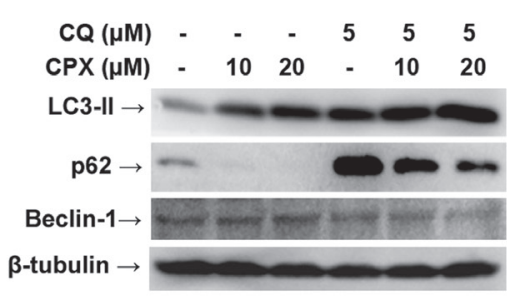

C

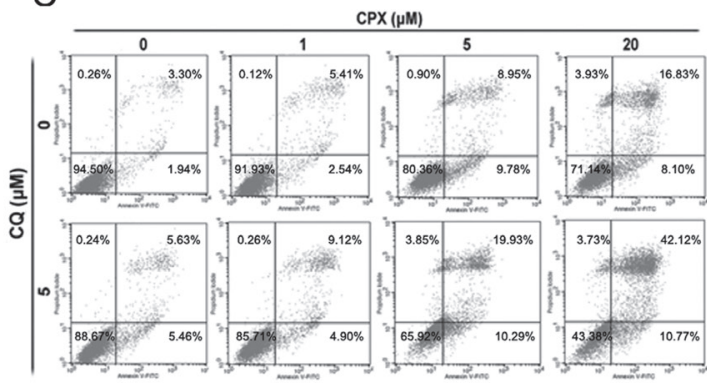

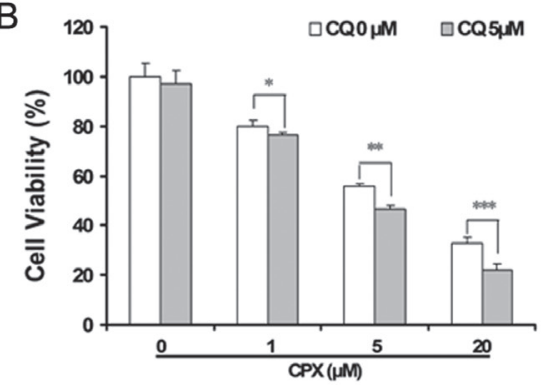

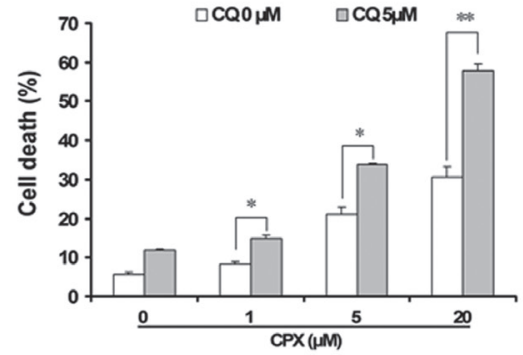

Figure 5: Inhibition of autophagy by CQ enhances CPX-induced autophagy and cell death. (A) RD cells were pretreated with $5 \mu \mathrm{M}$ of CQ for $1 \mathrm{~h}$, and then incubated with $0-20 \mu \mathrm{M}$ of CPX for $24 \mathrm{~h}$. The cells were harvested and subjected to Western blot analysis with indicated antibodies. $\beta$-tubulin was used as a loading control. (B) RD cells were pretreated with $5 \mu \mathrm{M}$ of CQ for $1 \mathrm{~h}$, and then incubated with $0-20 \mu \mathrm{M}$ of CPX for $48 \mathrm{~h}$. Cell viability was measured by MTS assay. Results are presented as mean \pm SD $(\mathrm{n}=3)$. ${ }^{*} P<0.05$, difference versus $1 \mu \mathrm{M} \mathrm{CPX}$ group, ${ }^{* *} P<0.01$, difference versus $5 \mu \mathrm{M}$ CPX group, ${ }^{* * * *} P<0.001$, difference versus $20 \mu \mathrm{M}$ CPX group. (C) RD cells were pretreated with $5 \mu \mathrm{M}$ of CQ for $1 \mathrm{~h}$, and then incubated with $0-20 \mu \mathrm{M}$ of CPX for $48 \mathrm{~h}$. The cells were then harvested and processed for Annexin V-FITC/PI staining and flow cytometry. Results are presented as mean $\pm \mathrm{SD}(\mathrm{n}=3)$. ${ }^{*} P<0.05$, difference versus $1 \mu \mathrm{M}$ and $5 \mu \mathrm{M}$ CPX group, respectively, ${ }^{* *} P<0.01$, difference versus $20 \mu \mathrm{M}$ CPX group.

CPX-induced apoptotic cell death (Figure 5C). These data suggest that autophagy protects rhabdomyosarcoma cells from CPX-induced cell death.

\section{DISCUSSION}

CPX is an off-patent drug and currently used for the treatment of skin and nail fungal infection [1]. Recently, $\mathrm{CPX}$ has also been found to possess anticancer properties, by inhibiting cell proliferation, inducing cell death, as well as inhibiting angiogenesis and lymphangiogenesis $[3,4,32,33]$. Oral administration of CPX at a dose of $20-25 \mathrm{mg} / \mathrm{kg} /$ day for 24-28 days inhibits the growth of xenografted leukemia (MDAY-D2, K562 and OCI-AML2) and primary human acute myeloid leukemia (AML) cells, as well as breast cancer (MDA-MB231) cells by $65-75 \%$ compared with vehicle control, but does not display evidence of weight loss or gross organ toxicity in mice $[3,4]$. Furthermore, a recent phase I clinical trial has demonstrated that oral administration of CPX at a dose of $40 \mathrm{mg} / \mathrm{m}^{2}$ once daily for 5 days is well tolerated in all patients without dose-limiting toxicity, displays persistent pharmacodynamic activity in the patients, and induces disease stabilization and/or hematologic improvement in $2 / 3$ patients with advanced hematologic malignancies [34]. Taken together, these findings highlight that CPX, as a fungicide, is a very promising anticancer agent and may be repurposed for cancer therapy.

Though CPX has been used as a fungicide for over 20 years, its antifungal mechanism is still not well understood. However, it has been proposed that CPX acts as an iron chelator, forming complexes with trivalent metal cations, such as $\mathrm{Fe}^{3+}$, and inhibiting iron-dependent enzymes, such as catalase and peroxidase, which catalyze degradation of toxic peroxides, resulting in oxidative toxicity in fungi [35]. Recently, it has been found that CPX induces cell death by chelating intracellular iron and inhibiting the iron-dependent enzyme ribonucleotide reductase in human leukemia and myeloma cells [4]. CPX induces apoptosis by increasing caspase- $3 / 7$ activity and down-regulating of protein expressions of $\mathrm{Bcl}-\mathrm{xL}$ and survivin in human rhabdomyosarcoma cells [3]. Furthermore, CPX inhibits Wnt/ $\beta$-catenin pathway [36], the mammalian target of rapamycin (mTOR) activity [37], and the eukaryotic translation initiation factor 5A (eIF5A) function $[32,38]$. It is unknown whether iron chelation is implicated in these effects of CPX. Clearly, the antitumor mechanism of CPX is complex and needs to be further investigated.

In the present study, for the first time, we found that CPX induced autophagy in human rhabdomyosarcoma $\mathrm{RD}$ and Rh30 cells. Although the precise mechanism of 
autophagy remains unclear, growing evidence has implicated that ROS play a critical role in controlling autophagy. ROS are highly reactive molecules formed by the incomplete one-electron reduction of oxygen, including oxygen ions and peroxides [39]. ROS form as a natural byproduct of the normal metabolism of oxygen and participate in cell signaling and homeostasis at low levels. However, under environmental stress, high levels of ROS can cause irreversible oxidative damage to cell structures [39]. Several stimuli that induce ROS generation can also induce autophagy, such as nutrient starvation, hypoxia, oxidative stress and some chemotherapeutic agents [7]. Alterations in ROS levels and autophagy play a crucial role in cancer initiation and progression, and both are recognized as the potential targets for cancer treatment $[31,40]$. Our present data showed that CPX induced ROS, which were detectable in $4 \mathrm{~h}$ and increased by approximately 2-fold in $24 \mathrm{~h}$ of treatment. NAC, the ROS scavenger, remarkably attenuated CPX-induced GFP-LC3 puncta formation and LC3-II expression. Our results suggest that CPX triggers autophagy by induction of ROS.

Multiple signaling molecules, such as MAPKs, mTOR, and class III PI3K, have been shown to regulate autophagy [24, 41]. The MAPKs, including ERK1/2, JNK and p38 MAPK, are a family of serine/threonine kinases that regulate a variety of cellular events such as proliferation and apoptosis [42]. It is well known that activation of JNK contributes to stress-induced apoptosis [42]. Recent studies have further revealed that activation of JNK is also associated with autophagy induction [24]. Endoplasmic reticulum (ER) stress induces autophagosome formation and accumulation by activation of inositol-requiring enzyme 1 (IRE1)-JNK pathway [43]. Bufalin induces autophagy via ROS induction and JNK activation [44]. Here we found that CPX was able to activate $\mathrm{p} 38 \alpha$, ERK1/2, and JNK1/2, but only activation of JNK pathway was responsible for CPX-induced autophagy. This is strongly supported by the findings that inhibition of JNK with SP600125 or ectopic expression of dominant negative c-Jun potently inhibited CPX-induced autophagy, whereas inhibition of ERK1/2 and p38 $\alpha$ using U0126 and doramapimod, respectively, failed to prevent CPX-induced autophagy. These results suggest that JNK pathway plays a critical role in CPX-induced autophagy. Our further study showed that pre-treatment with NAC prevented CPX-induced phosphorylation of c-Jun and autophagy, indicating that CPX-induced autophagy is dependent on ROS-activated JNK cascade. Further research is needed to address whether CPX induces autophagy also by targeting mTOR and class III PI3K.

Recent studies have shown that several anticancer agents including tamoxifen, 5-fluorouraci and rapamycin can induce autophagy [45-47]. However, the role of autophagy in cancer therapy is complex and controversial. It has been reported that increased autophagy may be pro-apoptotic [48] or pro-survival [45], depending on experimental conditions (cell types and anticancer agents). Some efforts have been made to find under what conditions autophagy can be exploited for cancer therapy. Of note, inhibition of autophagy enhances vorinostat or tamoxifen-induced apoptosis [46, 49]. Here we observed that disruption of autophagy using CQ increased CPXinduced apoptosis, indicating that CPX-induced autophagy is a pro-survival mechanism in rhabdomyosarcoma cells.

In conclusion, we show that CPX induced autophagy in human rhabdomyosarcoma cells. CPXinduced autophagy was mediated by ROS induction and JNK activation. Disruption of autophagy using CQ enhanced CPX-induced cell death, indicating that CPXinduced autophagy is a pro-survival mechanism in the cells. Our findings suggest that combination of CPX and an autophagy inhibitor (e.g. CQ) may be a promising strategy for cancer therapy.

\section{MATERIAL AND METHODS}

\section{Cell culture, agents and antibodies}

Human rhabdomyosarcoma (Rh30 and RD) cell lines (gifts from Peter J. Houghton, Nationwide Children's Hospital, Columbus, $\mathrm{OH}$ ) were grown in antibiotic-free RPMI 1640 (Mediatech, Herndon, VA) supplemented with $10 \%$ fetal bovine serum (FBS) (Atlanta Biologicals, Lawrenceville, GA). Rh30 cells stably expressing green fluorescent protein-light chain 3 (GFPLC3) were generated by transfection of Rh30 cells with pEGFP-LC3 plasmid (Addgene, Cambridge MA) using Lipofectamine 2000 (Life Technologies, Grand Island, NY) and selection with G418 (500 $\mu \mathrm{g} / \mathrm{ml})$ (Mediatech). Cells were maintained in a humid incubator $\left(37^{\circ} \mathrm{C}, 5 \%\right.$ $\mathrm{CO}_{2}$ ). Ciclopirox olamine (CPX) (Sigma, St. Louis, MO) was dissolved in $100 \%$ ethanol to prepare a stock solution $(100 \mathrm{mM})$, then aliquoted and stored at $-20^{\circ} \mathrm{C}$. Enhanced chemiluminescence solution was from PerkinElmer Life Science (Boston, MA, USA). CellTiter $96^{\circledR}$ $\mathrm{AQ}_{\text {uеous }}$ One Solution Cell Proliferation Assay kit was from Promega (Madison, WI). Annexin V-FITC Apoptosis Detection Kit I was purchased from BD Biosciences (San Jose, CA). U0126, SP600125 and doramapimod were obtained form LC Laboratories (Woburn, MA). $\mathrm{N}$-acetylcysteine (NAC), AO and CQ were purchased from Sigma. 5-6-chloromethyl-2,7-dichlorodihydrofluorescein diacetate (CM-H $\mathrm{H}_{2}$ DCFDA) was from Life Technologies. The following antibodies were used: p-JNK (Thr183/ Tyr185), JNK, p-c-Jun (Ser63), c-Jun, ERK2, p-p38 (Thr180/Tyr182), p38 $\alpha / \beta, \quad$ p62, Beclin-1, MAP LC3 $\beta$ (Santa Cruz Biotechnology, Santa Cruz, CA), phospho-p44/42 MAPK (ERK1/2) (Thr202/Tyr204) (Cell Signaling, Beverly, MA), $\beta$-tubulin, FLAG (Sigma), goat anti-rabbit IgG-horseradish peroxidase (HRP), goat antimouse IgG-HRP, and rabbit anti-goat IgG-HRP (Pierce, Rockford, IL). 


\section{Cell viability assay}

Cell viability was determined by MTS (3-(4, 5-dimethylthiazol-2-yl)-5-(3-carboxymethoxyphenyl)2-(4-sulfophenyl)-2H-tetrazolium, inner salt) assay, according to the protocol of CellTiter $96^{\circledR} \mathrm{AQ}_{\text {ueous }}$ One Solution Cell Proliferation Assay kit (Promega). Briefly, $100 \mu \mathrm{l}$ of cell suspensions were seeded into each well of 96-well plates $\left(1 \times 10^{4}\right.$ cells/well $)$ and incubate overnight. The cells were then exposed to the tested compounds in triplicates for $72 \mathrm{~h}$, followed by adding $20 \mu \mathrm{l}$ of One Solution Reagent per well. After further incubation at $37^{\circ} \mathrm{C}$ for $1-2 \mathrm{~h}$, cell viability was determined by measuring the optical density (OD) at $490 \mathrm{~nm}$ using a Wallac 1420 Multilabel Counter (PerkinElmer Life Sciences, Wellesley, MA).

\section{Cell morphological analysis}

Rh30 and RD cells were seeded in 6-well plates $\left(2 \times 10^{5} \mathrm{cells} / \mathrm{well}\right)$. The next day, the cells were treated with CPX $(0,5$ and $20 \mu \mathrm{M})$. After incubation for $72 \mathrm{~h}$, images were taken with an Olympus inverted phasecontrast microscope (Olympus Optical Co., Melville, NY) $(200 \times)$ equipped with the Quick Imaging system.

\section{Apoptosis assay}

Cells were pre-incubated with or without $5 \mu \mathrm{M}$ of CQ for $1 \mathrm{~h}$, and then treated with or without CPX $(1,5$ and $20 \mu \mathrm{M})$ for $48 \mathrm{~h}$. Cells were then collected and stained using Annexin V-FITC Apoptosis Detection Kit I (BD Biosciences) according to the manufacturer's instruction. In brief, cells were washed with cold PBS, and then resuspended in $100 \mu \mathrm{l}$ of Annexin- $\mathrm{V}$ binding buffer, followed by incubation with FITC conjugated Annexin V and propidium iodide (PI) for $15 \mathrm{~min}$ at room temperature in the dark. Flow cytometry was performed using a FACS Calibur flow cytometer (Becton Dickinson, San Jose, CA). Cells treated with vehicle alone (100\% ethanol) were used as a control.

\section{ROS detection}

Intracellular level of ROS was measured by detecting the fluorescent intensity of oxidant-sensitive probe $\mathrm{CM}-\mathrm{H}_{2} \mathrm{DCFDA}$, which is taken up by cells, cleaved by esterases to DCFH and trapped intracellularly. Briefly, Rh30 and RD cells were seeded at a density of $1 \times 10^{4}$ cells/well in 96-well plates. The next day, the cells were pre-incubated with or without NAC $(5 \mathrm{mM})$ for $30 \mathrm{~min}$, and then treated with or without CPX $(0-20 \mu \mathrm{M})$ for $30 \mathrm{~min}$, followed by loading with $10 \mu \mathrm{M}$ of CM- $\mathrm{H}_{2}$ DCFDA. At different time points (2, 4, 8 and $\left.24 \mathrm{~h}\right)$, the fluorescent intensity was detected by excitation at 485 $\mathrm{nm}$ and emission at $535 \mathrm{~nm}$ using a Wallac 1420 Multilabel Counter (Perkin-Elmer Life Sciences, Wellesley, MA).

\section{GFP-LC3 puncta assay}

Rh30 cells stably expressing GFP-LC3 were seeded at a density of $2 \times 10^{5}$ cells/well in 6 -well plates. The next day, the cells were treated without or with $20 \mu \mathrm{M}$ of CPX for different time ( 8 and $24 \mathrm{~h}$ ), or with different concentrations of CPX $(0-20 \mu \mathrm{M})$ for $24 \mathrm{~h}$, and examined under a fluorescence microscope.

\section{Western blot analysis}

Cells were seeded in 6-well plates at a density of $5 \times 10^{5}$ cells/well. The next day, the cells were treated with CPX $(0-20 \mu \mathrm{M})$ for $24 \mathrm{~h}$, or with $20 \mu \mathrm{M} \mathrm{CPX}$ for 0-24 h. For experiments with NAC or MAPK inhibitors, cells were pre-incubated with or without NAC or MAPK inhibitors for $1 \mathrm{~h}$, respectively. The cells were then treated with or without CPX $(10$ and $20 \mu \mathrm{M})$ for $24 \mathrm{~h}$. Cell lysis and immunoblotting were performed as described previously [3]. $\beta$-tubulin served as a loading control.

\section{Infection of cells with recombinant adenovirus}

Recombinant adenoviruses expressing FLAGtagged dominant negative c-Jun (FLAG- $\Delta 169)$ (Ad-c-Jun$\mathrm{DN}$ ) and green fluorescence protein (GFP) (Ad-GFP) were described [50]. For experiments, RD cells were seeded in 6 -well plates at a density of $5 \times 10^{5}$ cells/well. The next day, the cells were infected with the Ad-c-Jun-DN or Ad-GFP (as a control) for $24 \mathrm{~h}$ at 5 of multiplicity of infection $(\mathrm{MOI}=5)$. The cells were then treated with CPX $(0-20 \mu \mathrm{M})$ for $24 \mathrm{~h}$, followed by cell viability, morphology, and Western blot analysis. Expression of FLAG-tagged dominant negative c-Jun was confirmed by Western blotting with antibody to FLAG.

\section{Statistical analysis}

Results were expressed as mean values \pm standard deviation (mean $\pm \mathrm{SD}$ ). The data were analyzed by oneway analysis of variance (ANOVA) followed by posthoc Dunnett's $t$-test for multiple comparisons. A level of $P<0.05$ was considered to be statistically significant.

\section{Conflict of interest statement}

The authors declare no conflict of interest.

\section{ACKNOWLEDGEMENTS}

This work was in part supported by National Institutes of Health (CA115414; S. Huang), American Cancer Society (RSG-08-135-01-CNE; S. Huang), Carroll-Feist Predoctoral Fellowship Award (T. Shen), the West Light Foundation of The Chinese Academy of Sciences (H. Zhou), the National Natural Science Foundation of China (No. 81302807, H. Zhou), 
100 Talents Program of the Chinese Academy of Sciences (Y. Li), Top Talents of Sciences and Technology of Yunnan Province (No. 2009CI120, Y. Li) and Basic Research Program of Yunnan Province (No. 2013FA047, Y. Li).

\section{REFERENCES}

1. Gupta AK, Skinner AR. Ciclopirox for the treatment of superficial fungal infections: a review. Int J Dermatol. 2003; 42:3-9.

2. Bohn M, Kraemer KT. Dermatopharmacology of ciclopirox nail lacquer topical solution $8 \%$ in the treatment of onychomycosis. J Am Acad Dermatol. 2000; 43: S57-69.

3. Zhou H, Shen T, Luo Y, Liu L, Chen W, Xu B, Han X, Pang J, Rivera CA, Huang S. The antitumor activity of the fungicide ciclopirox. Int J Cancer. 2010; 127: 2467-2477.

4. Eberhard Y, McDermott SP, Wang X, Gronda M, Venugopal A, Wood TE, Hurren R, Datti A, Batey RA, Wrana J, Antholine WE, Dick J, Schimmer AD. Chelation of intracellular iron with the antifungal agent ciclopirox olamine induces cell death in leukemia and myeloma cells. Blood. 2009; 114:3064-3073.

5. Levine B, Kroemer G. Autophagy in the Pathogenesis of Disease. Cell. 2008; 132:27-42.

6. Wirawan E, Vanden Berghe T, Lippens S, Agostinis P, Vandenabeele P. Autophagy: for better or for worse. Cell Res. 2012; 22:43-61.

7. Lee J, Giordano S, Zhang J. Autophagy, mitochondria and oxidative stress: cross-talk and redox signalling. Biochem J. 2012; 441:523-540.

8. Deegan S, Saveljeva S, Gorman AM, Samali A. Stressinduced self-cannibalism: on the regulation of autophagy by endoplasmic reticulum stress. Cell Mol Life Sci. 2013; 70:2425-2441.

9. Jia K, Thomas C, Akbar M, Sun Q, Adams-Huet B, Gilpin C, Levine B. Autophagy genes protect against Salmonella typhimurium infection and mediate insulin signaling-regulated pathogen resistance. Proc Natl Acad Sci USA. 2009; 106:14564-14569.

10. Maryanovich M, Gross A. A ROS rheostat for cell fate regulation. Trends Cell Biol. 2013; 23:129-134.

11. Scherz-Shouval R, Elazar Z. Regulation of autophagy by ROS: physiology and pathology. Trends Biochem Sci. 2011; 36:30-38.

12. Chen Y, McMillan-Ward E, Kong J, Israels SJ, Gibson SB. Oxidative stress induces autophagic cell death independent of apoptosis in transformed and cancer cells. Cell Death Differ. 2008; 15:171-182.

13. Scherz-Shouval R, Shvets E, Fass E, Shorer H, Gil L, Elazar Z. Reactive oxygen species are essential for autophagy and specifically regulate the activity of Atg4. Embo J. 2007; 26:1749-1760.

14. Kyriakis JM, Avruch J. Mammalian MAPK signal transduction pathways activated by stress and inflammation: a 10-year update. Physiol Rev. 2012; 92:689-737.

15. Owens DM, Keyse SM. Differential regulation of MAP kinase signalling by dual-specificity protein phosphatases. Oncogene. 2007; 26:3203-3213.

16. Cagnol S, Chambard JC. ERK and cell death: mechanisms of ERK-induced cell death--apoptosis, autophagy and senescence. Febs J. 2010; 277:2-21.

17. Nithianandarajah-Jones GN, Wilm B, Goldring CE, Muller J, Cross MJ. ERK5: structure, regulation and function. Cell Signal. 2012; 24:2187-2196.

18. Wang X, Tournier C. Regulation of cellular functions by the ERK5 signalling pathway. Cell Signal. 2006; 18: 753-760.

19. Ono K, Han J. The p38 signal transduction pathway: activation and function. Cell Signal. 2000; 12:1-13.

20. Zhang J, Harrison JS, Studzinski GP. Isoforms of p38MAPK gamma and delta contribute to differentiation of human AML cells induced by 1,25-dihydroxyvitamin $\mathrm{D}_{3}$. Exp Cell Res. 2011; 317:117-130.

21. Sui X, Kong N, Ye L, Han W, Zhou J, Zhang Q, He C, Pan H. p38 and JNK MAPK pathways control the balance of apoptosis and autophagy in response to chemotherapeutic agents. Cancer Lett. 2014; 344:174-179.

22. He W, Wang Q, Srinivasan B, Xu J, Padilla MT, Li Z, Wang X, Liu Y, Gou X, Shen HM, Xing C, Lin Y. A JNKmediated autophagy pathway that triggers c-IAP degradation and necroptosis for anticancer chemotherapy. Oncogene. 2014; 33:3004-3013.

23. Lorin S, Pierron G, Ryan KM, Codogno P, Djavaheri-Mergny M. Evidence for the interplay between JNK and p53-DRAM signalling pathways in the regulation of autophagy. Autophagy. 2010; 6:153-154.

24. Davis RJ. Signal transduction by the JNK group of MAP kinases. Cell. 2000; 103:239-252.

25. Wong CH, Iskandar KB, Yadav SK, Hirpara JL, Loh T, Pervaiz S. Simultaneous induction of non-canonical autophagy and apoptosis in cancer cells by ROS-dependent ERK and JNK activation. PLoS One. 2010; 5:e9996.

26. Ni Z, Wang B, Dai X, Ding W, Yang T, Li X, Lewin S, $\mathrm{Xu}$ L, Lian J, He F. HCC cells with high levels of Bcl-2 are resistant to ABT-737 via activation of the ROS-JNKautophagy pathway. Free Radic Biol Med. 2014; 70: 194-203.

27. Kabeya Y, Mizushima N, Ueno T, Yamamoto A, Kirisako T, Noda T, Kominami E, Ohsumi Y, Yoshimori T. LC3, a mammalian homologue of yeast Apg8p, is localized in autophagosome membranes after processing. Embo J. 2000; 19:5720-5728. 
28. Moscat J, Diaz-Meco MT. p62 at the Crossroads of Autophagy, Apoptosis, and Cancer. Cell. 2009; 137: 1001-1004.

29. Cui Q, Tashiro S, Onodera S, Minami M, Ikejima T. Oridonin induced autophagy in human cervical carcinoma HeLa cells through Ras, JNK, and P38 regulation. J Pharmacol Sci. 2007; 105:317-325.

30. Arai T, Ohno M, Inoue H, Hayashi S, Aoki T, Hirokawa H, Meguro H, Koga Y, Oshida K, Kainoh M, Suyama K, Kawai H. Design and synthesis of novel p38 $\alpha$ MAP kinase inhibitors: discovery of pyrazole-benzyl ureas bearing 2-molpholinopyrimidine moiety. Bioorg Med Chem Lett. 2012; 22:5118-5122.

31. Mah LY, Ryan KM. Autophagy and cancer. Cold Spring Harb Perspect Biol. 2012; 4:a008821.

32. Clement PM, Hanauske-Abel HM, Wolff EC, Kleinman HK, Park MH. The antifungal drug ciclopirox inhibits deoxyhypusine and proline hydroxylation, endothelial cell growth and angiogenesis in vitro. Int J Cancer. 2002; 100:491-498.

33. Luo Y, Zhou H, Liu L, Shen T, Chen W, Xu B, Han X, Zhang F, Scott RS, Alexander JS, Alam A, Huang S. The fungicide ciclopirox inhibits lymphatic endothelial cell tube formation by suppressing VEGFR-3-mediated ERK signaling pathway. Oncogene. 2011; 30:2098-2107.

34. Minden MD, Hogge DE, Weir SJ, Kasper J, Webster DA, Patton L, Jitkova Y, Hurren R, Gronda M, Goard CA, Rajewski LG, Haslam JL, Heppert KE. Oral ciclopirox olamine displays biological activity in a phase I study in patients with advanced hematologic malignancies. Am J Hematol. 2014; 89:363-368.

35. Gupta AK. Ciclopirox: an overview. Int J Dermatol. 2001; 40:305-310.

36. Kim Y, Schmidt M, Endo T, Lu D, Carson D, SchmidtWolf IG. Targeting the Wnt/beta-catenin pathway with the antifungal agent ciclopirox olamine in a murine myeloma model. In Vivo. 2011; 25:887-893.

37. Sen S, Hassane DC, Corbett C, Becker MW, Jordan CT, Guzman ML. Novel mTOR inhibitory activity of ciclopirox enhances parthenolide antileukemia activity. Exp Hematol. 2013; 41:799-807:e794.

38. Memin E, Hoque M, Jain MR, Heller DS, Li H, Cracchiolo B, Hanauske-Abel HM, Pe'ery T, Mathews MB. Blocking eIF5A Modification in Cervical Cancer Cells Alters the Expression of Cancer-Related Genes and Suppresses Cell Proliferation. Cancer Res. 2014; 74:552-562.

39. Martindale JL, Holbrook NJ. Cellular response to oxidative stress: signaling for suicide and survival. J Cell Physiol. 2002; 192:1-15.
40. Hale AN, Ledbetter DJ, Gawriluk TR, Rucker EB 3rd. Autophagy: Regulation and role in development. Autophagy. 2013; 9:951-972.

41. Kim J, Kundu M, Viollet B, Guan KL. AMPK and mTOR regulate autophagy through direct phosphorylation of Ulk1. Nat Cell Biol. 2011; 13:132-141.

42. Ki YW, Park JH, Lee JE, Shin IC, Koh HC. JNK and p38 MAPK regulate oxidative stress and the inflammatory response in chlorpyrifos-induced apoptosis. Toxicol Lett. 2013; 218:235-245.

43. Ogata M, Hino S, Saito A, Morikawa K, Kondo S, Kanemoto S, Murakami T, Taniguchi M, Tanii I, Yoshinaga K, Shiosaka S, Hammarback JA, Urano F, et al. Autophagy is activated for cell survival after endoplasmic reticulum stress. Mol Cell Biol. 2006; 26:9220-9231.

44. Xie CM, Chan WY, Yu S, Zhao J, Cheng CH. Bufalin induces autophagy-mediated cell death in human colon cancer cells through reactive oxygen species generation and JNK activation. Free Radic Biol Med. 2011; 51: 1365-1375.

45. Pan X, Zhang X, Sun H, Zhang J, Yan M, Zhang H. Autophagy inhibition promotes 5-fluorouraci-induced apoptosis by stimulating ROS formation in human non-small cell lung cancer A549 cells. PLoS One. 2013; 8:e56679.

46. Amaravadi RK, Yu D, Lum JJ, Bui T, Christophorou MA, Evan GI, Thomas-Tikhonenko A, Thompson CB. Autophagy inhibition enhances therapy-induced apoptosis in a Myc-induced model of lymphoma. J Clin Invest. 2007; 117:326-336.

47. Li X, Wu D, Shen J, Zhou M, Lu Y. Rapamycin induces autophagy in the melanoma cell line M14 via regulation of the expression levels of Bcl-2 and Bax. Oncol Lett. 2013; 5:167-172.

48. Salazar M, Carracedo A, Salanueva IJ, Hernandez-Tiedra S, Lorente M, Egia A, Vazquez P, Blazquez C, Torres S, Garcia S, Nowak J, Fimia GM, Piacentini M, et al. Cannabinoid action induces autophagy-mediated cell death through stimulation of ER stress in human glioma cells. J Clin Invest. 2009; 119:1359-1372.

49. Carew JS, Medina EC, Esquivel JA 2nd, Mahalingam D, Swords R, Kelly K, Zhang H, Huang P, Mita AC, Mita MM, Giles FJ, Nawrocki ST. Autophagy inhibition enhances vorinostat-induced apoptosis via ubiquitinated protein accumulation. J Cell Mol Med. 2010; 14:2448-2459.

50. Han X, Xu B, Beevers CS, Odaka Y, Chen L, Liu L, Luo Y, Zhou H, Chen W, Shen T, Huang S. Curcumin inhibits protein phosphatases $2 \mathrm{~A}$ and 5 , leading to activation of mitogen-activated protein kinases and death in tumor cells. Carcinogenesis. 2012; 33:868-875. 